See Article page 91.

\section{Commentary: Coronary revascularization following aortic valve replacement: More than just a trivial event?}

\author{
Laurent Faroux, MD, ${ }^{a}$ Dimitri Kalavrouziotis, MD, ${ }^{b}$ \\ Josep Rodés-Cabau, MD, ${ }^{\mathrm{a}}$ and \\ Siamak Mohammadi, MD $^{\mathrm{b}}$
}

Degenerative aortic stenosis and coronary artery disease (CAD) share similar pathophysiological processes. ${ }^{1} \mathrm{~A}$ high proportion of patients with severe aortic stenosis have some degree of CAD, with a prevalence of CAD in transcatheter aortic valve replacement (TAVR) recipients of approximately $50 \% .^{2}$ In randomized trials comparing TAVR and surgical aortic valve replacement (SAVR), coronary revascularization at the time of the replacement operation was performed in approximately $12 \%$ of patients (either by percutaneous coronary intervention $[\mathrm{PCI}]$ or coronary artery bypass graft $[\mathrm{CABG}])$, and this proportion reached $25 \%$ in real-world TAVR registries. ${ }^{2}$ Three recent studies investigated the incidence, clinical characteristics, and outcomes of acute coronary syndrome (ACS) following $\mathrm{TAVR}^{3-5}$; however, most aspects of coronary events following SAVR have not been completely elucidated.

In this issue of the Journal, Çelik and colleagues ${ }^{6}$ report the risk of late coronary events among 420 patients who underwent isolated SAVR with a mean follow-up of 17 years.

From the Divisions of a Cardiology and ${ }^{\mathrm{b}}$ Cardiac Surgery, Quebec Heart and Lung Institute, Laval University, Quebec City, Quebec, Canada.

Disclosures: Dr Faroux has received fellowship support from Institut Servier and the Association Régionale de Cardiologie de Champagne-Ardenne and research grants from Biotronik, Edwards Lifesciences, and Medtronic. Dr Rodés-Cabau holds the Research Chair at the Fondation Famille Jacques Larivière for the development of structural heart disease interventions and has received institutional research grants from Medtronic and Edwards Lifesciences. All other authors reported no conflicts of interest.

The Journal policy requires editors and reviewers to disclose conflicts of interest and to decline handling or reviewing manuscripts for which they may have a conflict of interest. The editors and reviewers of this article have no conflicts of interest.

Received for publication May 17, 2020; revisions received May 17, 2020; accepted for publication May 20, 2020; available ahead of print June 25, 2020.

Address for reprints: Siamak Mohammadi, MD, Department of Cardiac Surgery, Quebec Heart and Lung Institute, 2725 Chemin Sainte-Foy, Quebec City, Quebec, Canada, G1V 4G5 (E-mail: siamak.mohammadi@fmed.ulaval.ca).

JTCVS Open 2020;3:104-5

2666-2736

Copyright (c) 2020 The Authors. Published by Elsevier Inc. on behalf of The American Association for Thoracic Surgery. This is an open access article under the CC BY-NCND license (http://creativecommons.org/licenses/by-nc-nd/4.0/).

https://doi.org/10.1016/j.xjon.2020.05.006

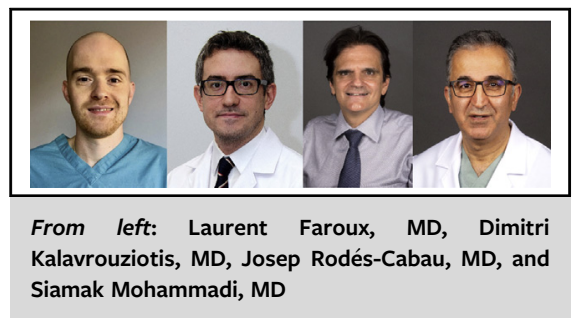

CENTRAL MESSAGE

Coronary revascularization was infrequent following surgical aortic valve replacement. Further studies in low-risk patients undergoing TAVR are needed to better assess the late need and outcomes of coronary revascularization.

The authors evaluated the incidence of coronary revascularization after isolated SAVR and the risk factors associated with late coronary revascularization post-SAVR. The study provides insight into the late incidence of coronary revascularization following SAVR; a rate of revascularization of 6.2 per 1000 patient-years was reported, along with an independent link between previous coronary interventions and the need for subsequent revascularization post-SAVR. The authors address a compelling clinical question, as the risk of late coronary disease may influence the selection of TAVR or SAVR for patients with severe aortic stenosis, and this is highly relevant for low-risk and younger patients. Nonetheless, some aspects of the authors' work merit further discussion.

First and foremost, patients were excluded if they had not been followed at the Erasmus Medical Center. These patients represented approximately $75 \%$ of all patients undergoing isolated SAVR, and thus the study's validity is seriously compromised by the likely profound selection bias. Only 24 patients underwent late coronary revascularization and were included in longitudinal analyses, and it is difficult to draw meaningful conclusions from these limited data. In addition, patients with concomitant CABG were not included in this study. This is relevant, given that approximately $30 \%$ of patients with aortic stenosis undergoing SAVR have concomitant $\mathrm{CABG}^{7}$ and $25 \%$ of TAVR recipients undergo PCI before TAVR. ${ }^{2}$ Thus, the authors' findings might not systematically apply to the whole spectrum of patients undergoing AVR. 
One of the stated objectives of the study was to provide relevant information regarding low-risk patients undergoing SAVR, which could then be applied to the low-risk TAVR population. Two recent studies including intermediate- to high-risk patients reported a rate of readmission for ACS after TAVR of 5\% after a median follow-up of 1 year and $10 \%$ after 2 years. ${ }^{3,5}$ In contrast, Çelik and colleagues report notably lower rates of coronary revascularization during follow-up, with $0.5 \%$ at 30 days, $2.2 \%$ at 1 year, $4.1 \%$ at 10 years and $6.9 \%$ at 20 years.

Several issues may have led to the authors' underestimation of the true coronary event burden following SAVR. Their data suggest that patients with previous revascularization are at highest risk of coronary revascularization following SAVR. However, patients with concomitant CABG were not included in the analysis. Also, approximately one-half of the study population underwent SAVR before 2002 , and $67 \%$ received a mechanical prosthesis, a practice that is no longer representative of the current management of surgical aortic stenosis. These patients were prescribed a lifelong vitamin $\mathrm{K}$ antagonist, which may have modulated the risk of a late coronary event. Finally, some of the observed deaths were probably related to a cardiac cause. Although considered in the statistical analyses, the competing risk of death may have led to underestimation of the coronary event burden, given that preceding mortality obviously decreases the risk of a coronary event requiring revascularization to zero.

Çelik and colleagues found that coronary revascularization during follow-up was more frequent in patients with previous revascularization before SAVR. This is not surprising, given that revascularization procedures are the most frequent cause of rehospitalization after PCI in patients with $\mathrm{ACS}^{8}{ }^{8}$ Of note, this result is consistent with findings of 2 previous studies that identified previous CAD as an independent predictor of ACS following TAVR. ${ }^{3-5}$ Owing to the advent of primary PCI, mortality following STelevation myocardial infarction (STEMI) and non-STelevation myocardial infarction is now similar. ${ }^{9}$ In contrast, STEMI following TAVR is associated with an increased risk of death compared with other types of ACS. ${ }^{4,5}$ It would be of value to compare the risks of death according to coronary event type among patients who underwent coronary revascularization after SAVR. Unfortunately, the small numbers of events did not allow Çelik and colleagues to investigate the prognostic factors predicting coronary events following SAVR, opening a new venue for future investigations.

In conclusion, this article by Çelik and colleagues examines the highly relevant issue of the late risk of coronary events following SAVR. In contrast, available data in TAVR cohorts come from intermediate- to high-risk populations. We caution readers to resist the urge to extrapolate the authors' data to the expected rate of coronary events in low-risk patients evaluated for TAVR. They likely underestimated the risk of late coronary revascularization, and their study design does not (and cannot) account for the alternative pathophysiological mechanisms linked to the transcatheter heart valve (eg, impaired coronary flow, leaflet thrombosis or late valve migration) leading to an ACS post-TAVR. ${ }^{2}$ Future studies focusing on low-risk patients undergoing TAVR are needed to better assess the incidence, clinical features, and outcomes of coronary revascularization following surgical AVR and TAVR.

\section{References}

1. Stewart BF, Siscovick D, Lind BK, Gardin JM, Gottdiener JS, Smith VE, et al Clinical factors associated with calcific aortic valve disease. Cardiovascular health study. J Am Coll Cardiol. 1997;29:630-4.

2. Faroux L, Guimaraes L, Wintzer-Wehekind J, Junquera L, Ferreira-Neto AN Del Val D, et al. Coronary artery disease and transcatheter aortic valve replacement: JACC state-of-the-art review. J Am Coll Cardiol. 2019;74: 362-72.

3. Vilalta V, Asmarats L, Ferreira-Neto AN, Maes F, Guimarães L, Couture T, et al Incidence, clinical characteristics, and impact of acute coronary syndrome following transcatheter aortic valve replacement. JACC Cardiovasc Interv. 2018;11:2523-33

4. Faroux L, Munoz-Garcia E, Serra V, Alperi A, Nombela-Franco L, Fischer Q, et al Acute coronary syndrome following transcatheter aortic valve replacement. Circ Cardiovasc Interv. 2020;13:e008620.

5. Mentias A, Desai MY, Saad M, Horwitz PA, Rossen JD, Panaich S, et al. Incidence and outcomes of acute coronary syndrome after transcatheter aortic valve replacement. JACC Cardiovasc Interv. 2020;13:938-50.

6. Çelik M, Durko AP, Head SJ, Mahtab EAF, van Mieghem NM, Cummins PA, et al. Coronary revascularization after surgical aortic valve replacement. J Thorac Cardiovasc Surg Open. 2020;3:91-101.

7. Malmberg M, Gunn J, Sipilä J, Pikkarainen E, Rautava P, Kytö V. Comparison of long-term outcomes of patients having surgical aortic valve replacement with versus without simultaneous coronary artery bypass grafting. Am J Cardiol. 2020;125:964-9.

8. Curtis JP, Schreiner G, Wang Y, Chen J, Spertus JA, Rumsfeld JS, et al. Allcause readmission and repeat revascularization after percutaneous coronary intervention in a cohort of Medicare patients. J Am Coll Cardiol. 2009;54: 903-7.

9. Puymirat E, Simon T, Cayla G, Cottin Y, Elbaz M, Coste P, et al. Acute myocardial infarction: changes in patient characteristics, management, and 6-month outcomes over a period of 20 years in the FAST-MI program (French registry of acute STelevation or non-ST-elevation myocardial infarction) 1995 to 2015. Circulation. 2017; 136:1908-19. 